\title{
Banco de Sementes de Plantas daninhas e sua Correlação com a Flora Estabelecida no Agroecossistema Cana-Crua ${ }^{1}$
}

\author{
Weed Seedbank and its Correlation with the Established Flora in No-Burn Sugarcane Area
}

\begin{abstract}
KUVA, M.A. ${ }^{2}$, PITELLI, R.A. ${ }^{3}$, ALVES, P.L.C.A. ${ }^{3}$, SALGADO, T.P. ${ }^{2}$ e PAVANI, M.C.D.M. ${ }^{3}$
RESUMO - O conhecimento da composição específica do banco de sementes de plantas daninhas e a sua correlação com a flora estabelecida são importantes para nortear o manejo a ser adotado e a escolha dos herbicidas. A colheita mecanizada de cana-de-açúcar acarretou mudanças significativas na composição da flora infestante, quando proporcionou a manutenção de uma camada de palha, reduziu a movimentação do solo e dispensou a prática da queimada. Foram realizados levantamentos do banco de sementes e da flora de plantas daninhas que se estabeleceu em 28 talhões colhidos mecanicamente, sem queima prévia da palha. Com base nos dados de banco de sementes, efetuaram-se estudos fitossociológicos e de correlação entre a composição do banco de sementes e a flora emergida. As principais espécies presentes no banco de sementes foram as pertencentes à classe das dicotiledôneas anuais, com destaque para Amaranthus spp. e diversas espécies de Euphorbiaceae e Convolvulaceae. As sementes de gramineas tradicionais da cultura tiveram pouca participação. O banco de sementes apresentou correlação não-significativa com a flora emergente, independentemente da época de colheita do talhão, da metodologia de quantificação do banco de sementes e das espécies de plantas daninhas.
\end{abstract}

Palavras-chave: cobertura morta, fitossociologia, Saccharum officinarum, correlação de Spearman Rank, coeficiente de similaridade.

\begin{abstract}
To set suitable weed management programs, one the most important parameters is knowing the specific composition of the seedbank and its correlation with the established flora. Such information is fundamental to guide the control strategy to be adopted and the herbicide choices. Mechanical harvest of no-burn sugar-cane maintaining a layer of straw on the soil surface promoted important changes in weed seed germination and seedling survival. Lack of soil mobilization and the lack of sugarcane burning are two additional factors influencing weed flora composition and population densities. Field sampling was conducted in twenty-eight no-burn sugarcane areas to evaluate (i) seedbank composition and seed population densities and later (ii) weed community composition and population density. A predominance of broad-leaf weeds was foud in the seed bank mainly Amaranthus spp., as well as species of the families Euphorbiaceae and Convulvulaceae. The traditional gramineous seeds were not profuse in the seedbanks of the studied areas. The correlation between the seedbank and the weed community compositions was small, regardless of the harvesting time, seedbank quantification methodology and weed species.
\end{abstract}

Keywords: mulching, phytosociology, Saccharum officinarum, Spearman Rank correlation, similarity coefficient.

1 Recebido para publicação 28.1.2008 e na forma revisada em 13.8.2008.

2 Engō-Agr ${ }^{0}$, Herbae Consultoria e Projetos Agrícolas Ltda. Rua José Antonio Fernandes Sobrinho, 118, Bairro Aparecida, Jaboticabal-SP, 14882-046, <mkuva@herbae.com.br ><tpsalgado@herbae.com.br $>$; ${ }^{3}$ Professores do Dep. de Biologia Aplicada à Agropecuária - Universidade Estadual Paulista - UNESP - Campus de Jaboticabal-SP, Via de acesso Prof. Paulo D. Castellane, s/n, Bairro Rural, Jaboticabal-SP, 14884-900.<rapitelli@ecosafe.agr.br>; <plalves@fcav.unesp.br>; <mcarmo@fcav.unesp.br>.

Planta Daninha, Viçosa-MG, v. 26, n. 4, p. 735-744, 2008 


\section{INTRODUÇÃO}

Roberts (1981) definiu banco de sementes como a reserva de sementes viáveis encontradas no solo. Essa reserva é um somatório de sementes produzidas e introduzidas ao longo do tempo e que se mantiveram vivas e dormentes, com sementes recém-produzidas. Assim, a composição do banco de sementes no agroecossistema cana-de-açúcar contém representantes do sistema atual de cultivo e de sistemas anteriores de cultivo da própria cana-de-açúcar ou associados a culturas anteriores. Isso ocorre porque a maioria das espécies de plantas daninhas possui adaptação para produzir grande número de sementes (Deuber, 1992), que muitas vezes apresentam grande longevidade (Burnside et al., 1986) e, ainda, mecanismos de dormência, distribuindo a germinação no tempo (Carmona, 1992).

O tamanho e a composição botânica do banco de sementes são variáveis em distintos habitats (Carmona, 1992). Para áreas cultivadas, Fenner (1995) estimou em 20.000 a 40.000 o número de sementes por metro quadrado. A composição do banco de sementes é influenciada pelas práticas culturais e varia de sistema para sistema (Benoit et al., 1992). Geralmente ele é composto por várias espécies, mas poucas são as dominantes (Wilson, 1988). As práticas de manejo de plantas daninhas, bem como as práticas culturais e de colheita adotadas no manejo da cana-de-açúcar, de modo geral, atuam e alteram a dinâmica de entrada e saída de sementes no banco, refletindo a médio e longo prazo na composição de espécies.

O sistema de cana-crua trouxe algumas modificações importantes no que se refere às plantas daninhas: reduziu a movimentação do solo; introduziu a colhedora como agente disseminador; eliminou o distúrbio pela queimada; e proporcionou a manutenção de uma camada de palha sobre o solo.

O decréscimo na movimentação do solo reduziu a incorporação de sementes recém-produzidas no solo e o resgate de sementes de outras gerações para a superficie. Com a eliminação desse efeito, as sementes ficam mais sujeitas ao desencadeamento da germinação, à predação e à perda de viabilidade (Yenish et al., 1992).

Planta Daninha, Viçosa-MG, v. 26, n. 4, p. 735-744, 2008
A manutenção de uma camada de palha altera a dinâmica dos principais herbicidas utilizados na cultura da cana-de-açúcar (Hernandez et al., 2001), funciona como barreira física à emergência e modifica importantes elementos microclimáticos, a composição microbiológica e o meio químico (Pitelli, 1998).

A predição da flora de plantas daninhas emergidas a partir de dados relativos ao banco de sementes, para possibilitar decisões antecipadas de controle numa lavoura, não tem sido uma tarefa fácil (Zhang et al., 1998). Persiste um potencial de erros de estimativa, para mais ou para menos, dependendo das condições ambientais que afetam a dormência e a germinação das sementes (Fenner, 1985).

O objetivo deste trabalho foi avaliar a composição específica do banco de sementes de plantas daninhas em áreas ocupadas pela cultura da cana-de-açúcar e a sua correlação com a flora de plantas daninhas estabelecida em canaviais com histórico de colheita mecanizada sem queima prévia da palha.

\section{MATERIAL E MÉTODOS}

Os dados utilizados neste trabalho foram obtidos durante a safra de 2004, em 29 talhões de cana-soca com histórico de mais de cinco anos de colheita mecanizada sem queima prévia da palha, localizados em usinas e fornecedores da região de Ribeirão Preto, SP. Foram amostrados talhões colhidos durante o mês de julho (época 1), a partir da segunda quinzena de agosto até meados de setembro (época 2) e nos meses de outubro e novembro (época 3 ). As informações mais importantes referentes aos talhões encontram-se na Tabela 1 . Os elementos meteorológicos registrados durante o período de coleta dos dados foram extraídos de um conjunto de dados pertencentes ao acervo da área de Agrometeorologia do Departamento de Ciências Exatas (Unesp - Jaboticabal) e encontram-se sumarizados na Figura 1.

Logo após o corte, cada talhão teve seu perímetro georreferenciado (GPS Garmim 12; software GPS Track Maker) e, quando necessário, foi limitado ao tamanho máximo de cinco hectares. Os talhões foram subdivididos em subtalhões com aproximadamente um hectare cada. No interior de cada subtalhão foram 
Banco de sementes de plantas daninhas e sua correlação...

Tabela 1 - Identificação, localização e informações mais relevantes dos talhões amostrados

\begin{tabular}{|c|c|c|c|}
\hline Talhão & Fazenda-Município & Data de corte & Cortes (crua) \\
\hline FSI-1 & Faz. Santa Isabel- Jaboticabal & $04 / 07 / 04$ & Quinto \\
\hline FBV-2 & Faz. Bela Vista - Jaboticabal & $16 / 07 / 04$ & Quinto \\
\hline NSF-3 & Faz. N. Sra. de Fátima - Taquaritinga & $02 / 07 / 04$ & Sexto \\
\hline FSC-4 & Faz. Sta. Cecília-Jaboticabal & $05 / 0704$ & Terceiro \\
\hline FBV-5 & Faz. Bela Vista - Jaboticabal & $19 / 07 / 04$ & Sexto \\
\hline UDP-6 & Usina da Pedra-Ribeirão Preto & $07 / 07 / 04$ & Quarto \\
\hline UAN-7 & Faz. Trindade - Pitangueiras & $30 / 07 / 04$ & Terceiro \\
\hline FSI-8 & Faz. Sta. Isabel- Jaboticabal & $27 / 07 / 04$ & Terceiro \\
\hline FSI-9 & Faz. Sta. Isabel- Jaboticabal & $25 / 07 / 04$ & Sétimo \\
\hline USB-10 & Faz. Diamantina - Taquaritinga & $14 / 05 / 04$ & Quinto \\
\hline USB-11 & Faz. Cucuhy-Guariba & $13 / 08 / 04$ & Terceiro \\
\hline COP-13 & Faz. Coplana-Guariba & $18 / 09 / 04$ & Segundo \\
\hline FM-14 & Faz. Morumbi-Guariba & $25 / 08 / 04$ & Terceiro \\
\hline FM-15 & Faz. Morumbi-Guariba & $28 / 08 / 04$ & Sexto \\
\hline FM -16 & Faz. Morumbi-Guariba & $05 / 09 / 04$ & Sexto \\
\hline FSA-17 & Faz. Sto. Antônio - Matão & $19 / 08 / 04$ & Terceiro \\
\hline FM -18 & Faz. Morumbi-Guariba & $12 / 09 / 04$ & Segundo \\
\hline USM-19 & Faz. Porto Pinheiro 17- Pradópolis & $03 / 09 / 04$ & Quinto \\
\hline USM-20 & Faz. Porto Pinheiro 17 - Pradópolis & $03 / 09 / 04$ & Quinto \\
\hline FSC-21 & Faz. Sta. Cecília- Jaboticabal & $12 / 09 / 04$ & Terceiro \\
\hline FBV-22 & Faz. Bela Vista - Jaboticabal & $08 / 10 / 04$ & Segundo \\
\hline FBV-23 & Faz. Bela Vista - Jaboticabal & $17 / 10 / 04$ & Quinto \\
\hline FBV-24 & Faz. Bela Vista - Jaboticabal & $17 / 10 / 04$ & Quarto \\
\hline FBV-25 & Faz. Bela Vista - Jaboticabal & $21 / 10 / 04$ & Primeiro \\
\hline FSO-26 & Faz. Santa Olívia-Jaboticabal & $06 / 11 / 04$ & Terceiro \\
\hline FSO-27 & Faz. Santa Olívia-Jaboticabal & $10 / 11 / 04$ & Sexto \\
\hline USM-28 & Faz. Barrinha-Barrinha & $28 / 10 / 04$ & Quinto \\
\hline USM-29 & Faz. Conceição - Jaboticabal & $13 / 11 / 04$ & Terceiro \\
\hline
\end{tabular}

demarcados cinco pontos para coleta e avaliação de banco de sementes e duas áreas quadradas ( $4 \times 4 \mathrm{~m}$ ), que ficaram livres da aplicação comercial de herbicidas, para coleta e avaliação da flora emergida.

As amostras para avaliação do banco de sementes foram coletadas logo após o corte, afastando-se a palha, na proporção de uma a cada hectare. Foram compostas por 50 subamostras cilíndricas $(5 \mathrm{~cm}$ de diâmetro por $10 \mathrm{~cm}$ de profundidade) coletadas ao redor dos cinco pontos diferentes (10 subamostras por ponto). Após a homogeneização, foram separados $2,5 \mathrm{~kg}$ de solo, que foram destinados ao Laboratório de Biologia e Manejo de Plantas Daninhas (Unesp - Jaboticabal). No laboratório, foi adotado o método da extração e contagem direta de sementes para estimativa do banco de sementes total (BST) e da contagem de plântulas emergidas acumuladas em três fluxos de emergência (BSF) em bandejas. Esses métodos foram propostos por Forcella \& Lindstrom (1988). Com os dados obtidos, foram realizados estudos fitossociológicos, sendo calculados os seguintes indices: densidade relativa (De.R.), freqüência relativa (Fr.R.) e importância relativa (IR), utilizando fórmulas contidas em Mueller Dombois \& Ellemberg (1974). A análise da participação de cada espécie na comunidade foi feita a partir dos dados de IR, calculados a partir da De.R. e Fr.R.

A flora estabelecida (FE) foi avaliada aos 120 dias após o corte da cana (DAC), determinando-se a densidade das espécies que 


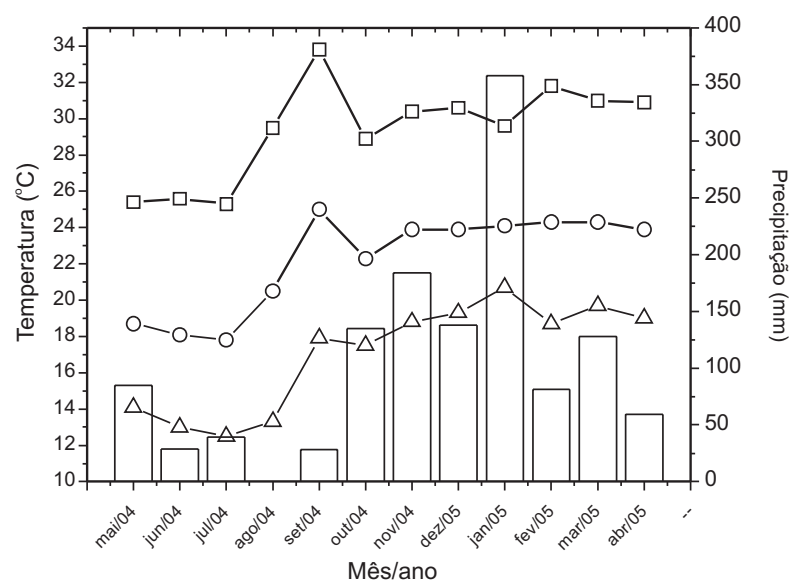

Fonte: Departamento de Ciências Exatas - Unesp Jaboticabal.

Figura 1 - Dados de precipitação (barras) e de temperaturas mínima $(\triangle)$, média $(\bigcirc)$ e máxima $(\square)$ registrados durante o período de coleta de dados.

compuseram cada um dos talhões, exceto um talhão, que sofreu aplicação indevida de herbicida em área total após a amostragem do banco de sementes. A avaliação foi feita por meio de quadrados vazados de $0,5 \times 0,5 \mathrm{~m}$, lançados ao acaso por quatro vezes nas entrelinhas da cultura, dentro de cada área demarcada mantida sem controle. As plantas abrangidas pelo quadrado foram identificadas e contadas, sendo consideradas somente plantas propagadas por sementes.

A correlação entre a composição específica do banco de sementes (BST e BSF) e da flora de plantas daninhas estabelecida (FE) foi estudada pela correlação de Spearman Rank, conforme Shiratsuchi (2001) e Cardina et al. (1996), e pelo coeficiente de similaridade (S) descrito em Odum (1985), calculado pela fórmula:

$$
\mathrm{S}=\left(2 \mathrm{~A}^{*}(\mathrm{~B}+\mathrm{C})^{-1}\right)^{*} 100
$$

sendo:

$\mathrm{A}=$ número de espécies comuns entre banco de sementes e flora emergida aos 120 DAC;

$\mathrm{B}=$ número de espécies do banco de sementes; e

$\mathrm{C}=$ número de espécies na flora emergida aos 120 DAC.

Planta Daninha, Viçosa-MG, v. 26, n. 4, p. 735-744, 2008

\section{RESULTADOS E DISCUSSÃO}

No banco de sementes dos primeiros $10 \mathrm{~cm}$ de profundidade foram encontradas sementes de 33 espécies de plantas daninhas. Considerando as sementes de todas as espécies encontradas e todos os talhões amostrados, a densidade média foi de 350 sementes $\mathrm{m}^{-2}$ (Tabela 2). Para Amaranthus spp., cujas sementes foram as mais numerosas e freqüentes, observaram-se, em média, 167 sementes $\mathrm{m}^{-2}$. Já para as duas espécies de cordade-viola, Ipomoea hederifolia e I. quamoclit, a quantidade de sementes encontradas foi, em média, de 83,3 e 38,4 sementes $\mathrm{m}^{-2}$, respectivamente. Os valores apresentados não representam o potencial de infestação imediato do talhão, pois englobam sementes provenientes da contagem direta e contabilizam também as sementes que originaram plântulas pelo método do fluxo de emergência, ou seja, sementes dormentes foram contabilizadas. O valor médio de 350,3 sementes $\mathrm{m}^{-2}$ ficou bem abaixo daqueles obtidos por Carmona (1995) para área de rotação de culturas anuais $(6.768$ sementes $\mathrm{m}^{-2}$ ), várzea (22.313 sementes $\mathrm{m}^{-2}$ ) e coroa de pomar de citros (3.595 sementes $\mathrm{m}^{-2}$ ) e pouco abaixo do obtido para área de pastagem (529 sementes $\mathrm{m}^{-2}$ ). $\mathrm{O}$ autor associou o gradiente de quantidade de sementes à freqüência de distúrbios, inserindo no extremo superior a várzea e no inferior a pastagem. Não há um levantamento abrangente de banco de sementes em áreas de colheita de cana queimada e corte manual - seguida de cultivo mecânico com implementos tradicionais que realizam movimentação do solo - que possa fornecer um valor médio do tamanho do banco de sementes nessas áreas. Contudo, é bastante claro que há redução na freqüência de distúrbio quando se adota a colheita mecanizada, pois a queimada é eliminada e a movimentação do solo reduzida.

Nos sistemas com movimentação vertical do solo reduzido, as sementes tendem a se concentrar nas camadas superficiais do solo e, na presença da camada de palha, parte das sementes recém-produzidas fica nela retidas. Como as subamostras atingiram até $10 \mathrm{~cm}$ de profundidade e foram coletadas mediante afastamento da palha, os valores obtidos podem estar subestimados, o que justifica a baixa densidade média obtida. 


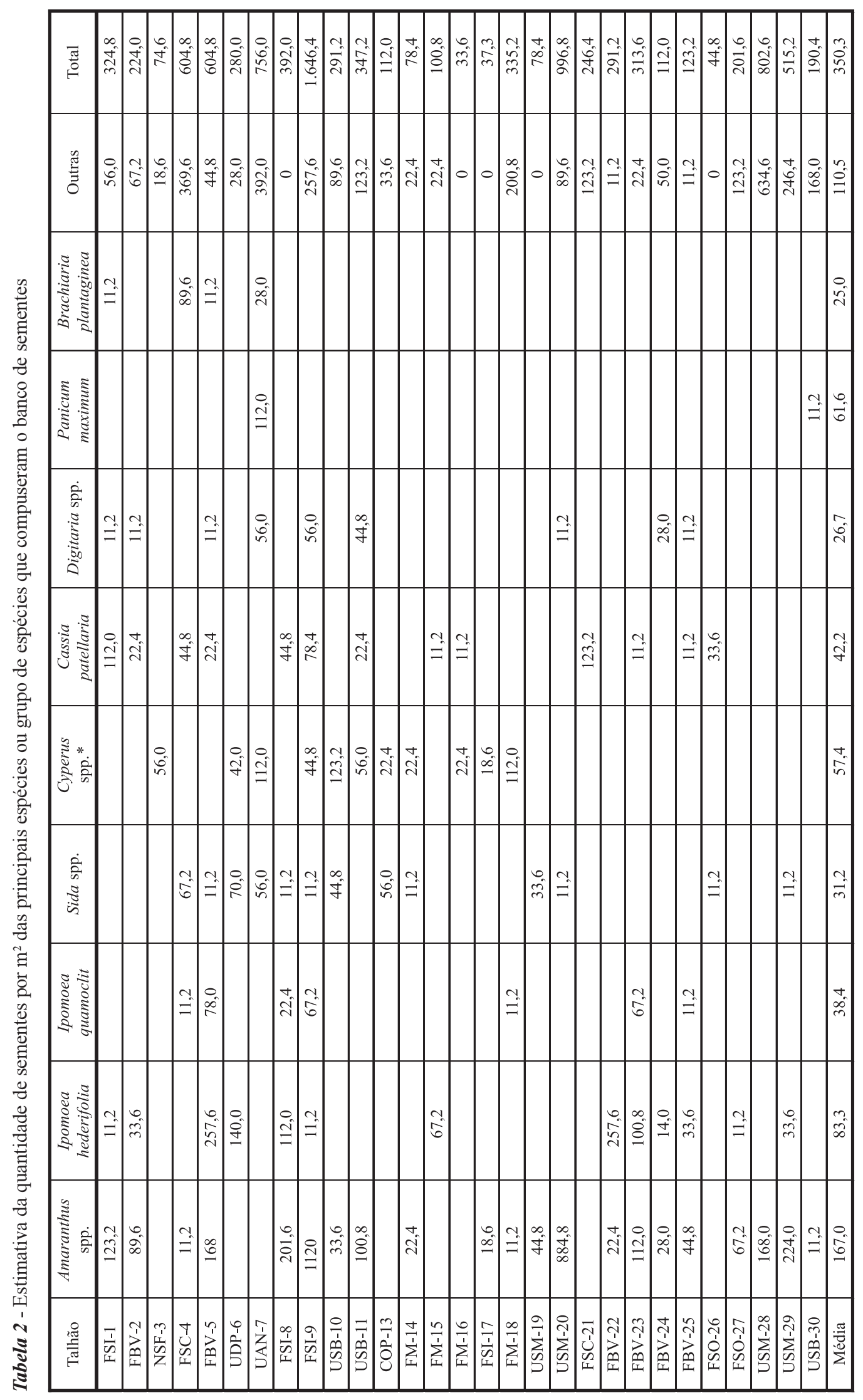


Analisando a relação das quatro principais espécies encontradas em cada talhão, ordenadas a partir da IR, constatou-se predominância de sementes de plantas daninhas anuais dicotiledôneas, entre as quais: Amaranthus spp., Portulaca oleraceae, Ipomoea spp., Euphorbia heterophylla, Sida spp., Chamaesyce hyssopifolia e Croton glandulosus (Tabela 3).

As sementes de Amaranthus spp. foram encontradas em 20 dos 29 talhões amostrados; em nove talhões, foi o principal componente do banco em razão da importância relativa. As diversas espécies de caruru estão entre aquelas que mais produzem descendentes (Deuber, 1992), os quais apresentam dormência, distribuindo sua germinação ao longo de vários anos.

Entre as espécies de corda-de-viola, destacaram-se Ipomoea hederifolia e Ipomoea quamoclit; a primeira constou entre as principais em 11 talhões, sendo em quatro deles a principal espécie (Tabela 3). Essas espécies produzem grande quantidade de sementes e, por serem relativamente grandes, possuem reserva suficiente para nutrir as plântulas durante a passagem através da camada de palha. Além disso, em várias ocasiões, os frutos com as sementes se mantêm ligados às plantas até a época da colheita, e a passagem da colhedora auxilia na sua disseminação a distâncias maiores.

As sementes das gramíneas mais importantes das áreas de colheita manual com queima prévia da palha encontradas neste estudo foram: Eleusine indica (quatro talhões), Digitaria spp. (cinco talhões), Brachiaria plantaginea (um talhão), Brachiaria decumbens (um talhão) e Panicum maximum (dois talhões). No entanto, somente a última espécie foi o principal destaque em um dos talhões. As sementes das gramineas, de modo geral, apresentam longevidade curta, e no sistema de cana-crua estão mais sujeitas à germinação seguida de morte ao tentarem transpassar a camada de palha e à predação por pequenos animais (Pitelli, 1998).

Também se destacaram sementes de Cyperus sp., que foram detectadas em dez talhões, sendo seis vezes como a principal componente do banco, e de Cassia patellaria, que foram detectadas em oito talhões, sendo duas vezes como a principal espécie (Tabela 3). Essa última espécie raramente é encontrada em canaviais como planta estabelecida e representa uma fração do banco de sementes que pode estar associada a ocupações anteriores e, devido à longevidade e dormência de suas sementes, ainda se faz presente em quantidade elevada.

Considerando a participação das duas principais espécies dentro dos talhões, constatou-se que respondem por mais de $50 \%$ do total das espécies em termos de importância relativa (Tabela 3). Segundo Wilson (1988), poucas espécies são as dominantes e respondem por 70 a $90 \%$ do total de sementes no solo.

O principal componente do banco de sementes, considerando todos os talhões, foi Amaranthus spp., com valor de importância relativa acumulada $(\Sigma I R)$ de 764,09 , bastante superior ao das demais espécies (Tabela 4). As demais plantas daninhas que se destacaram foram as Cyperaceas anuais e dicoliledôneas anuais (Euphorbiaceae, Asteraceae, Mimosaceae e Convolvulaceae). Quanto às espécies da família Convolvulaceae, observou-se presença mais significativa de Ipomoea hederifolia e Ipomoea quamoclit, que ocuparam o terceiro e o décimo lugar, respectivamente. As espécies Digitaria spp., Panicum maximum e Brachiaria plantaginea, de grande ocorrência nas áreas com histórico de colheita com queima prévia da palha, ocuparam o $11^{\circ}$, 16으 e 17임 lugares, respectivamente.

As correlações de Spearman Rank mostraram que o banco de sementes, na proporção e da maneira com que foi realizada a amostragem no campo, foi pouco eficiente para estimar a flora que se estabeleceu, independentemente da época de corte da cana e do método laboratorial de determinação do banco de sementes utilizado (Tabela 5) e das espécies consideradas (Tabela 6). Shiratsuchi (2001) utilizou essa correlação para eleger quais espécies poderiam ter seu controle baseado em mapas de distribuição de banco de sementes no solo e obteve correlações altamente significativas e com boa estabilidade ao longo do tempo para Ageratum conyzoides e Commelina benghalensis em áreas de plantio direto. Entretanto, sua amostragem foi bem mais intensa, pois foi realizada numa área menor e considerando o método dos quadrantes para a coleta das amostras 


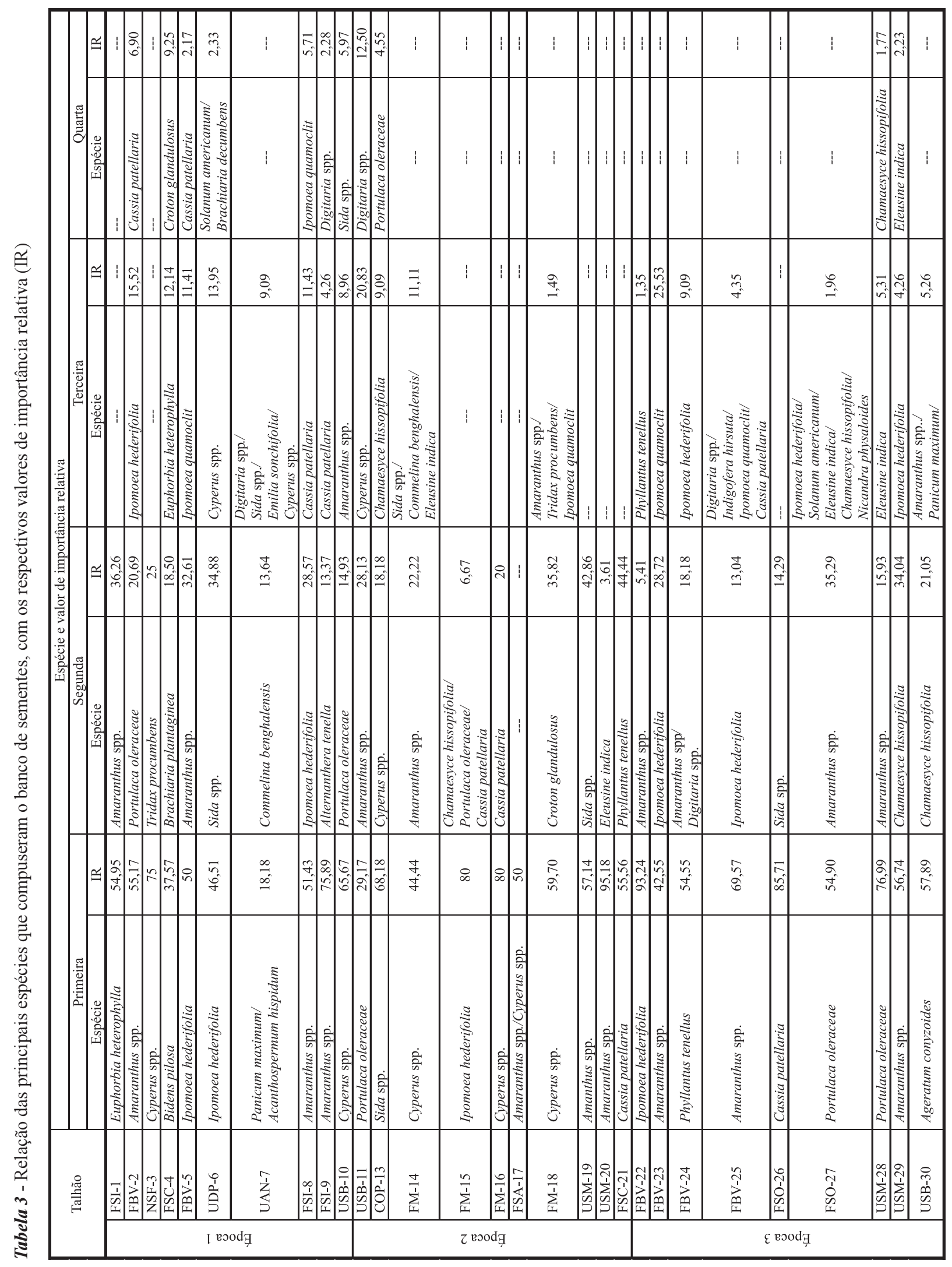


Tabela 4 - Espécies encontradas nos talhões e ordenadas pela importância relativa acumulada, calculada a partir dos dados de banco de sementes

\begin{tabular}{|c|c|c|}
\hline Posição & Planta daninha & $\Sigma \mathrm{IR}$ \\
\hline $1^{\underline{0}}$ & Amaranthus spp. & 764,09 \\
\hline $2^{\underline{0}}$ & Cyperus spp. ${ }^{*}$ & 438,70 \\
\hline $3^{0}$ & Ipomoea hederifolia & 372,17 \\
\hline $4^{\underline{0}}$ & Cassia patellaria & 262,07 \\
\hline $5^{0}$ & Portulaca oleraceae & 211,84 \\
\hline $6^{0}$ & Sida spp. & 197,82 \\
\hline $7^{\underline{0}}$ & Phyllanthus tenellus & 106,32 \\
\hline $8^{\underline{0}}$ & Chamaesyce hissopifolia & 85,71 \\
\hline $9^{0}$ & Ageratum conyzoides & 57,89 \\
\hline $10^{\underline{0}}$ & Ipomoea quamoclit & 50,90 \\
\hline $11^{\mathrm{o}}$ & Digitaria spp. & 50,01 \\
\hline $12^{\underline{0}}$ & Croton glandulosus & 45,07 \\
\hline $13^{\mathrm{o}}$ & Bidens pilosa & 38,67 \\
\hline $14^{\underline{9}}$ & Tridax procumbens & 26,49 \\
\hline $15^{0}$ & Commelina benghalensis & 24,90 \\
\hline $16^{\mathrm{o}}$ & Panicum maximum & 23,44 \\
\hline $17^{\underline{0}}$ & Brachiaria plantaginea & 22,41 \\
\hline $18^{\underline{0}}$ & Acanthospermum hispidum & 18,70 \\
\hline $19^{0}$ & Euphorbia heterophylla & 13,95 \\
\hline $20^{\underline{0}}$ & Alternanthera tenella & 13,37 \\
\hline
\end{tabular}

* Exceto Cyperus rotundus. Obs.: não foram consideradas estruturas de propagação vegetativa.

(20 x $20 \mathrm{~m}$ ), para posterior confecção de mapas de distribuição. Correlações significativas entre banco de sementes e plântulas emergidas também foram obtidas nos experimentos realizados por Cardina et al. (1996) e Cardina \& Sparrow (1996), mas sempre em condições de pequenas parcelas.

Utilizando os coeficientes de similaridade (S), que consideram somente a presença ou ausência das espécies para correlacionar o banco de sementes e a flora estabelecida aos 120 DAC, observou-se que os valores foram
Tabela 5 - Correlação de Spearman Rank resultante da comparação entre banco de sementes e a flora estabelecida aos 120 DAC

\begin{tabular}{|c|c|c|c|}
\hline \multirow{2}{*}{ Comparação } & \multicolumn{3}{|c|}{ Época de corte } \\
\cline { 2 - 4 } & Época 1 & Época 2 & Época 3 \\
\hline BST x FE & $0,015197 \mathrm{~ns}$ & $0,005812 \mathrm{~ns}$ & $-0,21769 \mathrm{~ns}$ \\
\hline BSF x FE & $0,157983 \mathrm{~ns}$ & $-0,18609 \mathrm{~ns}$ & $0,04026 \mathrm{~ns}$ \\
\hline
\end{tabular}

Com base em dados de todas as áreas dentro de cada época de corte.

BST - banco de sementes total (contagem);

BSF - banco de sementes (fluxo);

FE - flora estabelecida aos 120 DAC.

bastante variáveis, apresentando coeficientes de similaridades muito baixos em alguns talhões e chegando a mais de $60 \%$ em outros (Tabela 7). Também não foi constatada grande variação em função da época de corte da cana. Os coeficientes de similaridade médios foram de 38,40, 29,45 e 33,09\% para as épocas 1, 2 e 3 , respectivamente.

Considerando que as amostragens de banco de sementes não detectam plantas originadas de propagação vegetativa ou rebrota, como Cyperus rotundus, Cynodon dactylon, Cissampelos glaberrima, Pyrostegia venusta, Talinum paniculatum e Vernonia polyanthes, essas correlações poderiam ser ainda menores.

Concluiu-se que o banco de sementes em áreas de cana-crua apresentou, em média, 350 sementes $\mathrm{m}^{-2}$. As principais espécies foram Amaranthus spp., Cyperus spp., Cassia patellaria, Ipomoea spp., Chamaesyce hissopifolia, Sida spp. e Phylantus tenellus, porém a correlação com a flora estabelecida aos 120 DAC foi baixa, independentemente da espécie de planta daninha e da época de colheita da cana-de-açúcar.

Tabela 6 - Correlação de Spearman Rank resultante da comparação entre banco de sementes de algumas das principais espécies (BST) com a flora estabelecida (FE) aos 120 DAC

\begin{tabular}{|c|c|c|c|c|c|}
\hline \multirow{2}{*}{ Comparação } & \multicolumn{5}{|c|}{ Espécie } \\
\cline { 2 - 6 } & Amaranthus spp. & Ipomoea hederifolia & Ipomoea quamoclit & Sida spp. & Digitaria spp. \\
\hline BST x FE & $0,24 \mathrm{~ns}$ & $0,37 \mathrm{~ns}$ & $-0,046 \mathrm{~ns}$ & $0,21 \mathrm{~ns}$ & $-0,009 \mathrm{~ns}$ \\
\hline
\end{tabular}

Com base em todas as áreas que apareceram representantes da espécie no banco de sementes ou na flora emergente.

BST - banco de sementes total (contagem);

FE - flora estabelecida aos 120 DAC. 
Tabela 7 - Coeficientes de similaridade entre a composição do banco de sementes e a flora de plantas daninhas estabelecida aos 120 DAC

\begin{tabular}{|c|c|c|c|c|c|}
\hline \multirow{2}{*}{ Época } & \multirow{2}{*}{ Talhão } & \multicolumn{3}{|c|}{ Número de espécies } & \multirow{2}{*}{ C. Odum (S) } \\
\hline & & BST & FE & Comuns ao BST e FE & \\
\hline \multirow{11}{*}{1} & FSI-1 & 10 & 7 & 3 & 35,29 \\
\hline & FBV-2 & 5 & 5 & 3 & 60 \\
\hline & NSF-3 & 2 & 8 & 1 & 20 \\
\hline & FSC-4 & 13 & 12 & 8 & 64 \\
\hline & FBV-5 & 11 & 9 & 6 & 60 \\
\hline & UDP-6 & 5 & 9 & 3 & 57,14 \\
\hline & UAN-7 & 13 & 9 & 3 & 27,27 \\
\hline & FSI-8 & 5 & 7 & 1 & 16,66 \\
\hline & FSI-9 & 9 & 9 & 4 & 44,44 \\
\hline & USB-10 & 6 & 0 & 0 & 0 \\
\hline & Média & & & & 38,40 \\
\hline \multirow{11}{*}{2} & USB-11 & 7 & 10 & 5 & 58,82 \\
\hline & COP-13 & 4 & 8 & 2 & 33,33 \\
\hline & FM-14 & 5 & 7 & 2 & 33,33 \\
\hline & FM-15 & 4 & 4 & 0 & 0 \\
\hline & FM-16 & 2 & 3 & 0 & 0 \\
\hline & FSA-17 & 2 & 3 & 0 & 0 \\
\hline & FM-18 & 5 & 4 & 2 & 44,44 \\
\hline & USM-19 & 2 & 3 & 2 & 80 \\
\hline & USM-20 & 6 & 2 & 1 & 25 \\
\hline & FSC-21 & 2 & 10 & 1 & 16,66 \\
\hline & Média & & & & 29,45 \\
\hline \multirow{9}{*}{3} & FBV-22 & 3 & 6 & 2 & 22,22 \\
\hline & FBV-23 & 6 & 7 & 1 & 15,38 \\
\hline & FBV-24 & 4 & 2 & 0 & 0 \\
\hline & FBV-25 & 6 & 4 & 1 & 20 \\
\hline & FBV-26 & 2 & 6 & 1 & 25 \\
\hline & FS0-27 & 7 & 7 & 1 & 28,57 \\
\hline & FSO-28 & 4 & 3 & 2 & 57,14 \\
\hline & FSO-29 & 8 & 2 & 2 & 40 \\
\hline & Média & & & & 33,09 \\
\hline
\end{tabular}

BST - banco de sementes total (contagem); FE - flora estabelecida aos 120 DAC.

\section{AGRADECIMENTOS}

Aos agrônomos e técnicos das usinas e fazendas envolvidas (Usina Bonfim, Usina da Pedra, Usina Andrade, Fazenda Santa Isabel, Fazenda Santa Cecília e Fazenda Santo Antonio), pelas diversas formas de apoio.

\section{LITERATURA CITADA}

BENOIT, D. L.; DARKSEN, D. A.; PANNETON, B. Innovative approaches to seedbank studies. Weed Sci., v. 40 , n. 4, p. 660-669, 1992.
BURNSIDE, O. C. et al. Weed seed density in soil in weed free-corn (Zea mays) production across Nebraska. Weed Sci., v. 34, n. 2, p. 248-251, 1986.

CARDINA, J.; SPARROW, D. H. A comparison of methods to predict weed seedling populations from the soil seedbank. Weed Sci., v. 44, n. 1 p. 46-51, 1996.

CARDINA, J.; SPARROW, D. H.; McCOY, E. L. Spatial relationships between seedbank and seedling populations of common lambsquarters (Chenopodium album) and annual grasses. Weed Sci., v. 44, n. 2, p. 298-308, 1996. 
CARMONA, R. Banco de sementes e estabelecimento de plantas daninhas em agroecossistemas. Planta Daninha, v. 13, n. 1, p. $3-9,1995$

CARMONA, R. Problemática e manejo de banco de semente de invasoras em solos agrícolas. Planta Daninha, v. 10, n. 1, p. $5-13,1992$.

DEUBER, R. Botânica das plantas daninhas. In: DEUBER, R. Ciências das plantas daninhas. Jaboticabal: FUNEP, 1992. p. 31-73.

FENNER, M. Ecology of seeds banks. In: KIGEL, J.; GALILI, G. (Eds.). Seed development and germination New York: Marcel Beckker, 1995. p. 507-528.

FENNER, M. Seed ecology. London: Chapman and Hall, 1985. $485 \mathrm{p}$

FORCELLA, F.; LINDSTROM, M. J. Weed seed populations in ridge and conventional tillage. Weed Sci., v. 36, n. 4, p. 500-503, 1988.

HERNANDEZ, D. D.; ALVES, P. L. C. A.; MARTINS, J. V. F. Influência do resíduo de colheita de cana-de-açúcar sem queima sobre a eficiência dos herbicidas imazapic e imazapic + pendimethalin. Planta Daninha, v. 19, n. 3, p. 419-426, 2001.
MUELLER-DOMBOIS, D.; ELLEMBERG, H. Aims and methods of vegetation ecology. New York: John Wiley \& Sons, 1974. 547 p.

ODUM, E. P. Ecologia. Rio de Janeiro: Interamericana, 1985. $434 \mathrm{p}$

PITELLI, R. A. Plantas daninhas no sistema plantio direto de culturas anuais. R. Plantio Direto, n. 47, p. 13-18, 1998.

ROBERTS, H. A. Seed banks in the soil. Cambridge: Academic Press, 1981.55 p. (Advances in Applied Biology, 6)

SHIRATSUCHI, L. S. Mapeamento da variabilidade espacial das plantas daninhas com utilização de ferramentas da agricultura de precisão. 2001. $96 \mathrm{f}$. Dissertação (Mestrado em Fitotecnia) - Escola Superior de Agricultura "Luiz de Queiroz", Piracibaba, 2001.

WILSON, R. G. Biology of weed seeds in the soil. In: ALTIERE,M.A.; LIEBMAN, M. (Eds). Weed management in agroecosystems: Ecological approaches. Boca Raton: CRP Press, 1988. p. 25-39.

YENISH, J. P.; DOLL, J. D.; BUHLER, D. D. Effects of tillage on vertical distribution and viability of weed seed in soil. Weed Sci., v. 40, n. 3, p. 429-433, 1992.

ZHANG, J. et al. Dependence of weed flora on the active soil seedbank. Weed Res., v. 38, n. 1, p. 143-152, 1998. 